\title{
THE INFLUENCE OF LINOLEIC ACID UPON THE GROWTH OF TRANSPLANTED SARCOMA
}

\author{
YUJI SUEYOSHI and YOSHIKAGE NAGAO \\ Department of Biochemistry, School of Medicine, Keio University, Tokyo
}

(Received for publication May 25, 1962)

In their previous work Sueyoshi and $\mathrm{Nagao}^{(1)}$ reported that the consumption of linoleic acid by tumor tissue is much greater than that of the normal muscle. This is probably due to the great need of linoleic acid by the tumor tissue for its growth. Based on this suggestion, one might expect the inhibitory effect of the withdrawal of linoleic acid from the diet for the growth of the tumor. Experiments have now been carried out in order to test the validity of this hypothesis.

\section{MATERIALS AND METHODS}

Albino rats of nonpure strain, weighing ca. $70 \mathrm{~g}$, are used as experimental animals and fed the diet with following component as normal basic diet.

$\begin{array}{lc}\text { Starch } & 72 \% \\ \text { Casein } & 18 \% \\ \text { Inorganic salts (McCollum) } & 4 \% \\ \text { Oryzanin powder (Vitamin B complex) } & 4 \% \\ \text { Biosterin (Vitamin A and D) } & 5 \text { drops }\end{array}$

The fat-free diet used in this experiment consists of starch and casein, from which fat has been extracted by the use of alcohol. Also, oryzanin powder was extracted with ether, unsaponifiable substances which were isolated from codliver oil were used instead of biosterin.

Fujinawa-strain sarcoma, transplanted to the rats, was used as experimental tumor tissue. The size of the tumor was showed by the orthographic projection.

\section{RESULTS}

Rats are placed on a fat-free diet for 3 weeks and then the Fujinawa-strain sarcoma is transplanted to the rats, which are divided into 2 experimental groups; the first group is placed on normal basic diet for 2 weeks thereafter and the second group is fed on a fat-free diet. The difference of the growth of the tumor tissue in these two groups at the end of the experiment is shown in Fig. I. 

As seen in Fig. I the growth of the tumor in the normal diet group (Group I), is much greater than that of the fat-free diet group (Group II). When expressed by surface area, the average surface area of the group I is $824 \mathrm{~mm}^{2}$ whereas that of the group II is $329 \mathrm{~mm}^{2}$, that is $1 / 3$ of the group I area. Most of the rats in group I died by the end of the 2 nd wk after tumor-transplantation and the remainder died within 16 days, whereas the rats in group II survived longer than 16 days, because of the smaller growth of the tumor tissue. The second experiment was carried out as follows. The rats (Group III) are treated as in group II and at the end of the 2 nd wk after the tumor-transplantion, linseed oil is added to the fat-free diet (linseed oil replaceing $20 \%$ of the starch in the fat-free diet). In 4 days after this diet change the tumor tissue grows so fast that the tumor extends as large as in group I. In another experiment when the rats (Group IV) are placed on a fat-free diet, to which only linoleic acid $(25 \mathrm{mg} /$ day $)$ is added after the tumor-transplantation, the growth of the tumor is as large as in the linseed oil diet group.

\section{CONCLUSION}

(1) The growth of the sarcoma in rats, when fed on fat-free diet, is much less than that of the normal diet fed group.

(2) Addition of linseed oil to the fat-free diet, which inhibits the growth of the tumor, shows faster growth of the sarcoma tissue. The same result is obtained by addition of linoleic acid to the fat-free diet.

(3) From above observations it might be concluded that linoleic acid is needed for the growth of the sarcoma and that the lack of this substance greatly inhibits the growth of the tumor.

\section{REFERENCE}

1. Sueyoshi, Y. and Nagao, Y.: Keio J. Med., 11: 25, 1962. 